\title{
ACUTE SEVERE MITRAL REGURGITATION WITH CARDIOGENIC SHOCK CAUSED BY TWO-STEP COMPLETE ANTERIOR PAPILLARY MUSCLE RUPTURE DURING ACUTE MYOCARDIAL INFARCTION
}

\author{
Martin Hutyra $^{\mathrm{a}}$, Tomas Skala ${ }^{\mathrm{a}}$, Dan Marek ${ }^{\mathrm{a}}$, Petr Nemec ${ }^{\mathrm{b}}$, Martin Sluka $^{\mathrm{c}}$, Jiri Ostranskyc, \\ Marek Richter ${ }^{\mathrm{c}}$, Jan Lukl ${ }^{\mathrm{c}}$
}

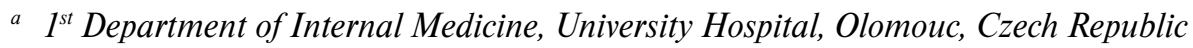 \\ ${ }^{b}$ Department of Cardiovascular Surgery, University Hospital, Olomouc \\ c $I^{\text {st }}$ Department of Internal Medicine, University Hospital, Olomouc \\ e-mail: martinhutyra@seznam.cz
}

Received: October 19, 2006; Accepted: November 9, 2006

Key words: Acute myocardial infarction/Mitral regurgitation/Papillary muscle rupture/Cardiogenic shock

Background: Rupture of a papillary muscle is an infrequent but often fatal mechanical complication of acute myocardial infarction.

Aim: The aim of this paper is to present a case report of a 65 -year old women with acute severe mitral regurgitation with cardiogenic shock caused by two-step complete anterior papillary muscle rupture during acute myocardial infarction. The transthoracic echocardiography was obtained at the bedside and showed a posterior mitral valve prolapse with a severe mitral regurgitation. During this examination the patient developed acute pulmonary oedema and a consequent cardiogenic shock. Transthoracic echocardiography was then reevaluated and completed. New findings of bi-leaflet mitral flail and progression of massive mitral regurgitation were documented. The complete rupture of a papilary muscle was then considered as a cause of an acute clinical deterioration. Intraoperative findings showed a complete transection of both heads of anterolateral and necrotic regions of basis of posteromedial papillary muscle.

Conclusions: This case confirms the importance of immediate echocardiography in confirming a diagnosis of acute mechanical complications of acute coronary syndromes and this examination is important for the management of a hemodynamically unstable patient. Echocardiography should be done immediately on any patient in whom the diagnosis of mechanical complication of acute coronary syndromes is suspected.

\section{BACKGROUND}

The rupture of a papillary muscle is an infrequent but often fatal mechanical complication of acute myocardial infarction. While it is rare, it is an important cause of severe mitral regurgitation, heart failure, cardiogenic shock and death ${ }^{1}$. A high suspicion of this complication based on a newly audible pansystolic murmur and an early diagnosis by echocardiography in a hemodynamically unstable patient plays the key role in the management of consecutive mitral valve surgery, without which the outcomes are almost poor ${ }^{2}$.

\section{CASE REPORT}

A 65-year old woman with coronary atherosclerosis risk factors (diabetes mellitus, hypertension, dyslipidemia, obesity, metabolic syndrom, cigarette smoking) was examined in an another hospital after sudden onset of chest pain. Diagnosis of non-ST elevation anterolateral acute coronary syndrom was established. After the initial stabilization with intravenous unfractionated heparin, nitroglycerin, metoprolol, oral acetylosalicylic acid and simvastatin the patient was transferred to the coronary care unit of our institution with an admission delay about 10 hours since onset of myocardial infarction for further management. At the initial clinical examination the patient was hypotensive with a blood pressure of $90 / 60 \mathrm{mmHg}$, pulse rate of 100 beats per minute and with the systolic murmur suspected of a mitral regurgitation, but no pulmonary rales were detected. Electrocardiography revealed sinus tachycardia and horizontal ST depressions in leads I, V2 trough V5 (Fig. 1).

The patient's creatine kinase (CK) levels peaked at $16.81 \mu \mathrm{kat} / 1, \mathrm{MB}-$ fraction (CK-MB) was $8.1 \%$ of total CK activity. The serum troponin $\mathrm{T}$ was $5.42 \mu \mathrm{g} / \mathrm{l}$, creatinine $180 \mu \mathrm{mol} / 1$, NT-pro-BNP at $24385 \mathrm{ng} / 1$ and C-reactive protein $551.5 \mathrm{mg} / 1$.

Coronary angiography revealed a single vessel disease with large circumlex coronary artery proximally occluded (Fig. 2). Otherwise, the coronary angiography findings were normal. Percutaneous coronary intervention (PCI) with balloon angioplasty and stenting of ramus circumflexus was performed successfully without complication and the patient was transferred back to the coronary care unit.

The transthoracic echocardiography (TTE) was obtained 2 hours after PCI and showed a posterior mitral 


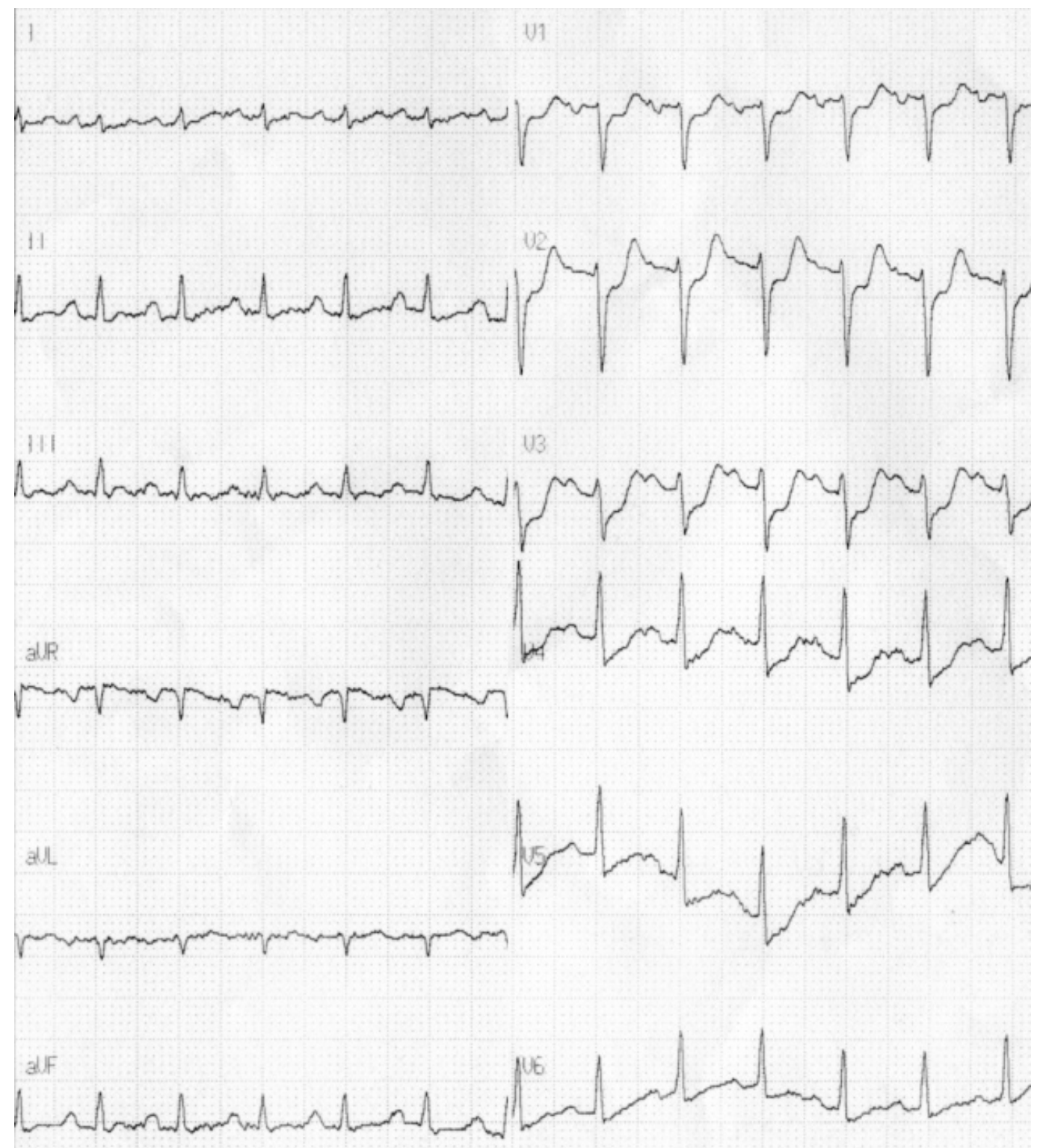

Fig. 1. Electrocardiogram recorded immediately on patient's admission at coronary care unit.

valve prolapse with a severe mitral regurgitation (Fig. 3), hypercontractile left ventricle with a posterolateral hypokinesis, normal left and right ventricular size and the left ventricle ejection fraction of 75-80\% (Fig. 4). The dimensions of left atrium in parasternal long axis and apical four chamber projections were normal. During this echocardiographic examination, cardiogenic shock and a consequent acute pulmonary oedema developed. A heart rate was 140 beats per minute, respiration was 40 per min. and invasive arterial blood pressure decreased to $50 / 20 \mathrm{mmHg}$. There was evidence of peripheral hypoperfusion. TTE was then reevaluated and completed. New findings of a bi-leaflet mitral flail and progression of a massive mitral regurgitation were documented (Fig. 5). The complete rupture of a papilary muscle was then considered as a cause of this acute clinical deterioration.

Intravenous inotropes were given and an intraaortic balloon contrapulsation was immediately inserted.
Endotracheal intubation and artificial ventilation with positive endexpiratory pressure was also required immediately. Pulmonary artery catheter was inserted for hemodynamical monitoring. There was an evidence of a venous pulmonary hypertension (pulmonary artery pressure 56/ $47 / 39 \mathrm{mmHg}$ ) with a low cardiac output (CO $3.21 \mathrm{~min}$.). The pulmonary wedge pressure during the initial rightheart catheterization was $33 \mathrm{mmHg}$.

Intraoperative findings were a completed transection of both heads of anterolateral muscle as well as the presence of necrotic regions in basis of the posteromedial papillary muscle. The patient underwent a successful mitral valve replacement with mechanical prosthesis St. Jude No. 25. The postoperative course was uneventful and also normalization of all laboratory tests was noted. The patient was discharged 18 days after operation in a very good physical condition, in NYHA class I with normal left ventricle diastolic and systolic size $(43 / 32 \mathrm{~mm})$, nor- 

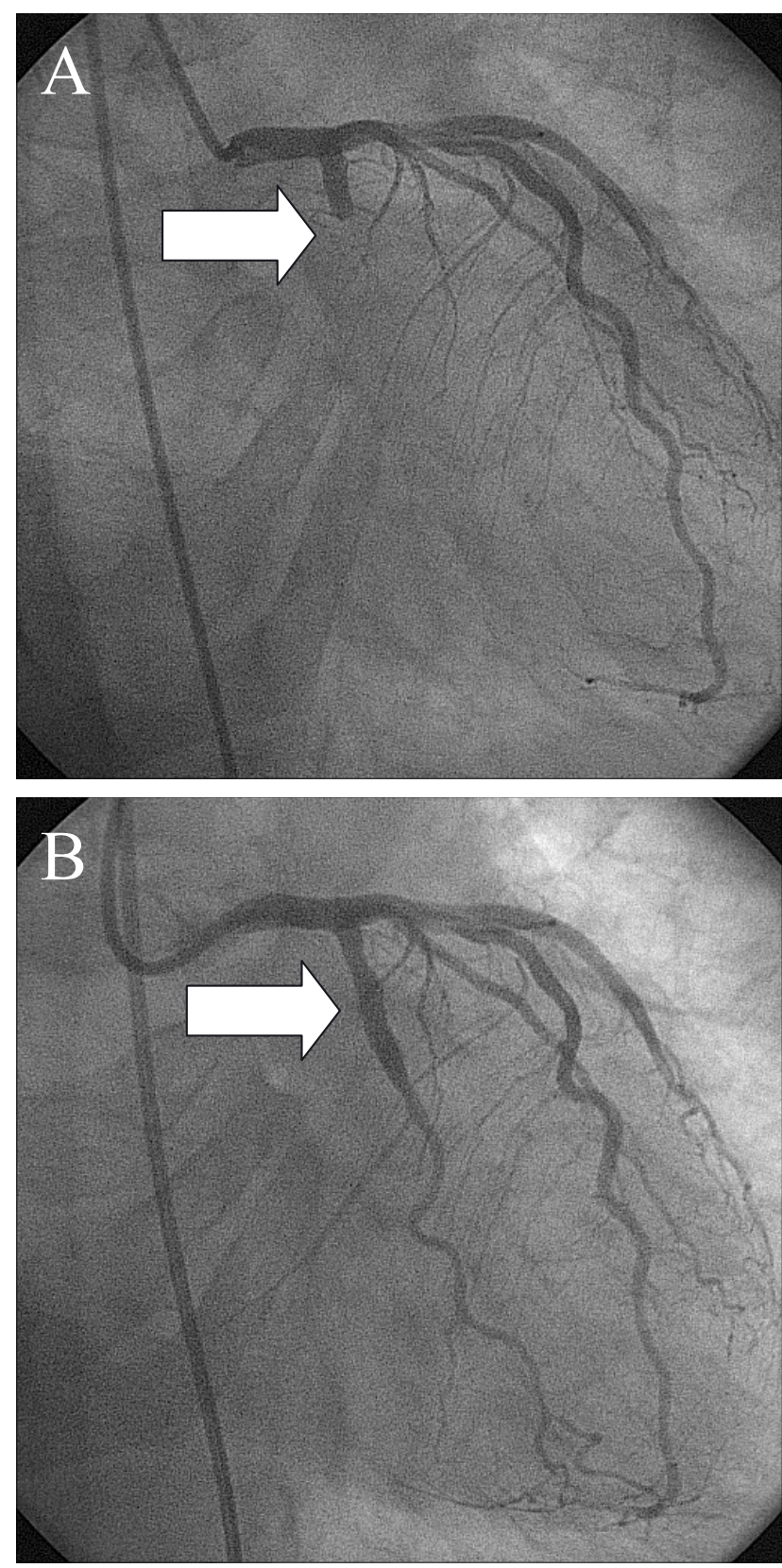

Fig. 2. Coronary angiogram shows occluded large proximal left circumflex artery (upper panel A). Injection of contrast agent into the left circumflex artery after successful PCI is shown in the lower panel B.

mal left ventricle ejection fraction $55 \%$. The left atrium was not enlarged (parasternal long axis diameter $36 \mathrm{~mm}$ ). 66 days after operation, the patient was hemodynamically stable in NYHA class I, with normal function of mechanical prosthesis and normal size and function of left ventricle.

\section{DISCUSSION}

Ischemia is the most common cause of papillary muscle rupture ${ }^{1-5}$. Non-ischemic causes such as endocarditis,

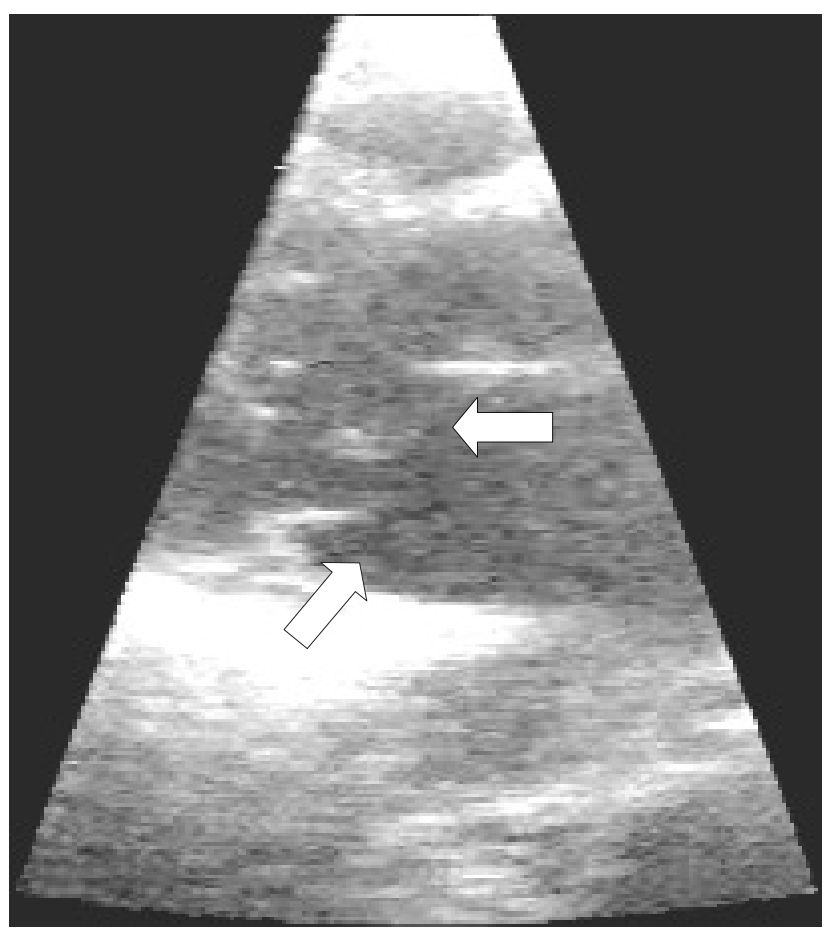

Fig. 3. Initial period of transthoracic echocardiography examination The posterior mitral leaflet flail (lower arrow) with normal mobility of the anterior mitral leaflet (upper arrow) on the parasternal long-axis view during the left ventricle systole is shown.

chest trauma, sepsis, intramural amyloidosis and spontaneous papillary muscle rupture are very rare ${ }^{6,7}$.

Chronic mitral regurgitation is relatively common after myocardial infarction and varies in clinical severity. It may exhibit a broad range of severity, from clinically evident and hemodynamically obvious to clinically silent, detected only as an incidental finding on catheterization or echocardiography. Acute papillary muscle rupture occurs as a rare mechanical complication of myocardial infarction ${ }^{1,4,8}$. Papillary muscle rupture complicates fewer then $1 \%$ of all patients with an acute myocardial infarction and represents about $5 \%$ of all cases of ischemic mitral regurgitation (4). Papillary muscle rupture carries an $80-90 \%$ mortality. Rupture of the posteromedial papillary muscle is five to ten times more frequent than rupture of the anterolateral papillary muscle ${ }^{1}$. Papillary muscle rupture typically occurs within the first week of an acute myocardial infarction. Partial papillary muscle rupture is more common then completed rupture. Rupture involving primary heads of papillary muscle causes severe acute mitral insufficiency followed rapidly by left ventricle heart failure, cardiogenic shock and death.

In this case we present the history of a patient with an acute mitral regurgitation with progression during transthoracic echocardiography examination, which demonstrated gradually a complete two-step rupture of anterolaterolal papillary muscle and flailing anterior and posterior mitral leaflets. Acute hemodynamic deterioration of the patient pointed to this mechanical compli- 


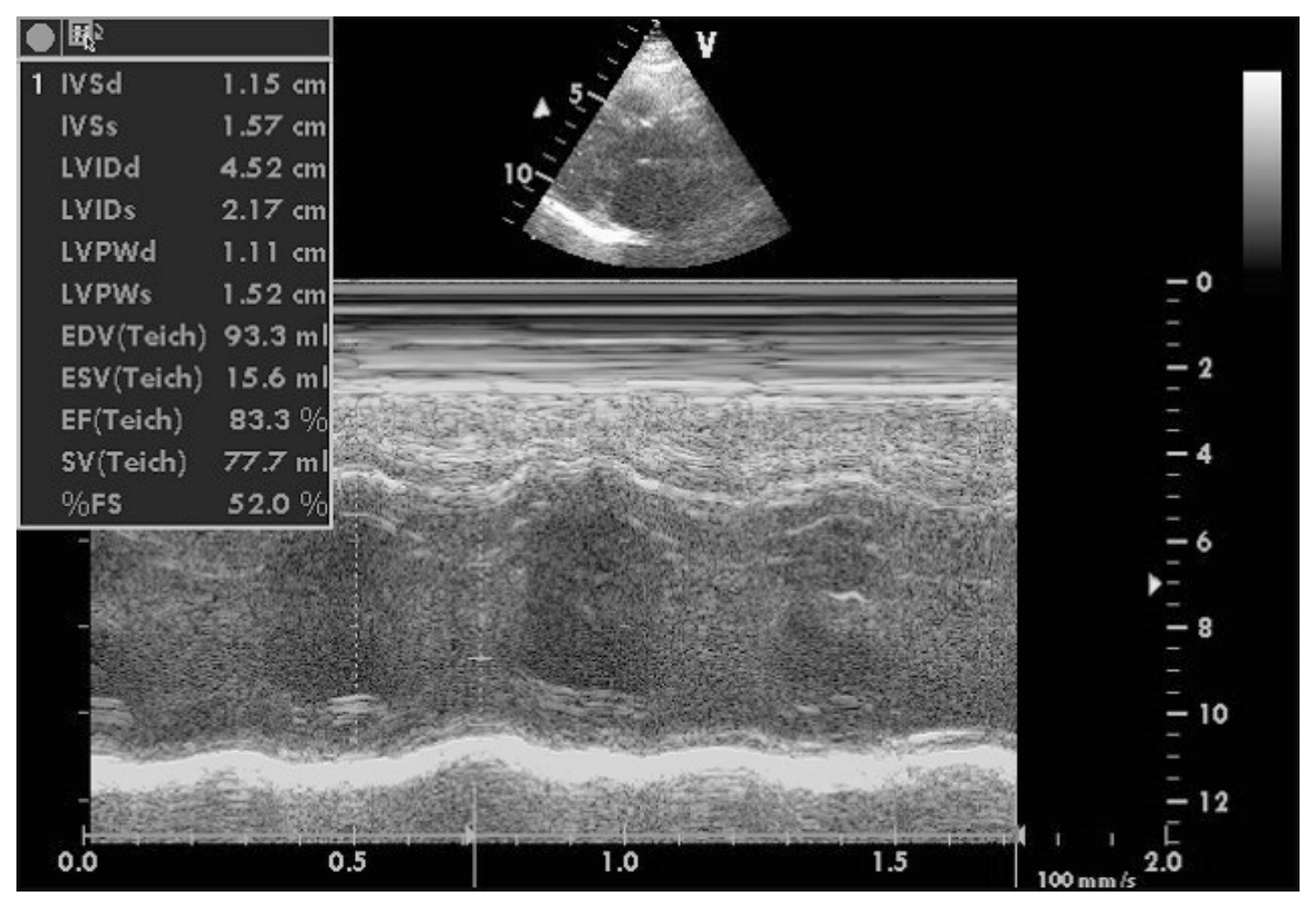

Fig. 4. Left ventricle M-mode echocardiography during initial echocardiography
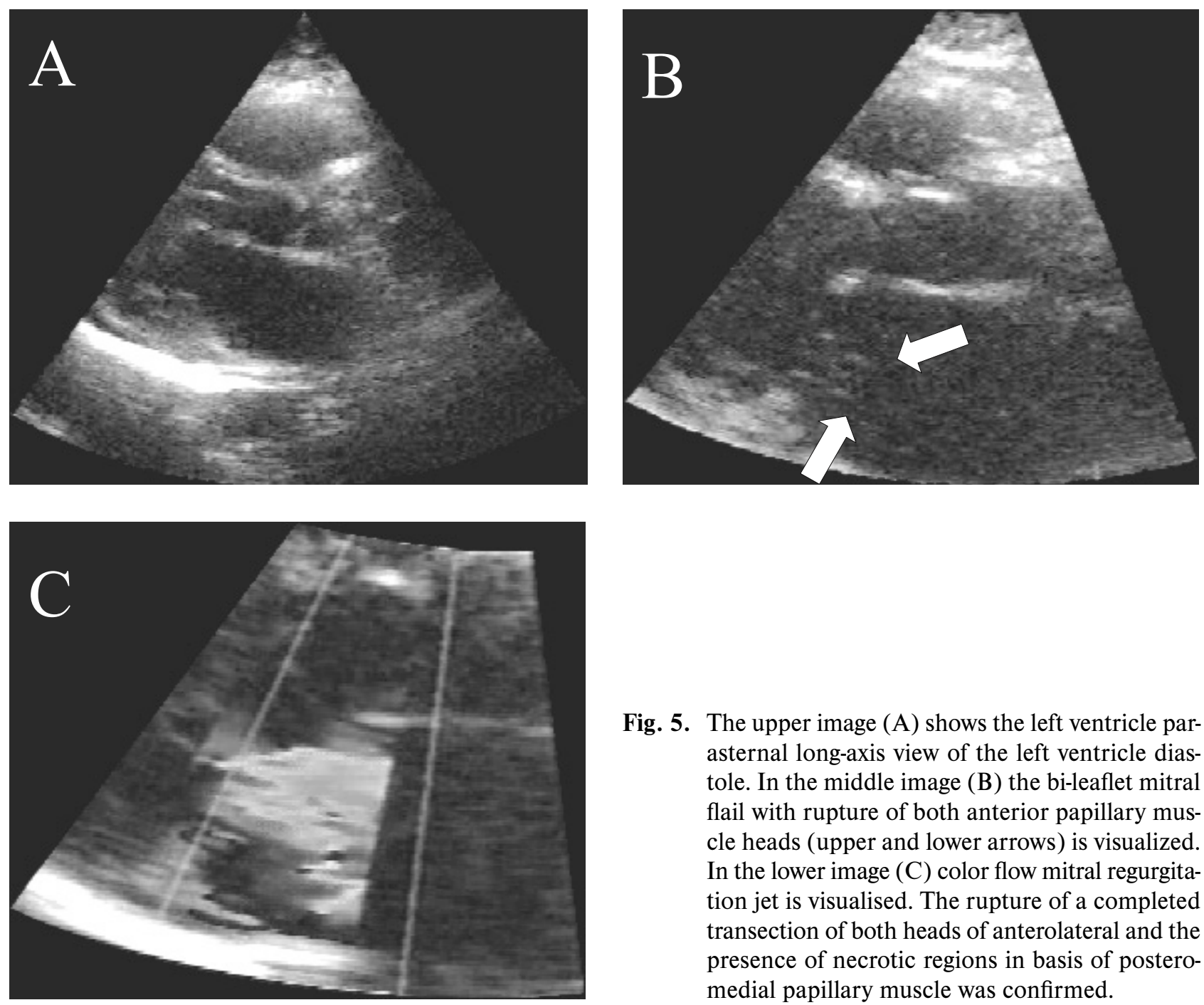

Fig. 5. The upper image (A) shows the left ventricle parasternal long-axis view of the left ventricle diastole. In the middle image (B) the bi-leaflet mitral flail with rupture of both anterior papillary muscle heads (upper and lower arrows) is visualized. In the lower image $(\mathrm{C})$ color flow mitral regurgitation jet is visualised. The rupture of a completed transection of both heads of anterolateral and the presence of necrotic regions in basis of posteromedial papillary muscle was confirmed. 
cation. Although papillary muscle rupture occurs with greater frequency in posteromedial papillary muscle, we present a case report of anterolateral papillary muscle transection and both mitral bi-leaflet flail with severe mitral regurgitation, which contrasts with the above mentioned published data. The predominant involvement of posteromedial papillary muscle in patients with inferior acute myocardial infarction in the location of papillary muscle rupture is due to a predominantly single blood supply ${ }^{8}$. Nevertheless the association of papillary muscle rupture with left circumflex coronary artery occlusion has been also demonstrated ${ }^{9}$.

A high index of suspicion is the key to an early diagnosis and the specific management of a hemodynamically compromised patient with specific mechanical complication of acute myocardial infarction. This case confirms the importance of immediate echocardiography in assessing a diagnosis of the acute mechanical complication and this examination is important for the management of a hemodynamically unstable patient. Therefore echocardiography should be obtained immediately for any patient in whom the diagnosis of the mechanical complication of acute coronary syndrome is suspected.

\section{REFERENCES}

1. Braunwald E, Zipes DP, Libby P. Heart disease, $6^{\text {th }}$ edition. W.B.Saunders Company, Philadelphia, 2001; 1184-1185.

2. Fasol R, Lakew F, Wetter S. Mitral repair in patients with a ruptured papillary muscle. Am Heart J, 2000; 139:549-554.

3. Verma R, Freeman I. Rupture of papillary muscle during acute myocardial infarction. N Engl J Med 1999; 341:247, 1999. Images in Clinical Medicine.

4. Gorman RC, Gorman JG III, Edmunds LH Jr. Ischemic mitral regurgitation. In: Cohn LH, Edmunds LH Jr, eds.: Cardiac surgery in the adult. McGraw-Hill, New York, 2003; 751-769.

5. McQuillan BM, Weyman AE. Severe mitral regurgitation secondary to partial papillary muscle rupture folowing myocardial infarction. Rev Cardiovascular Med. 2000; 1(1):57-60.

6. Schulz R, Andreas S, Weisse B. Acute papillary muscle rupture in a patient with clostridial sepsis (Case report). J Intern Med 1997, 241:253-255.

7. Coisne D, Corbin P, Sosner P. Obstructive intramural coronary amyloidosis and papillary muscle rupture. Heart 2003; 89:e8.

8. Choi-Keung Ng, Nesser J, Punzengruber J, Pandian NG, Khanderia B, Hartl P et al. Modern mitral valve repair. Echocardiographic interpretations and surgical strategies. Springer-Verlag, Wien, 2003; 96-98.

9. Figueras J, Calvo F, Cortadellas J, Soler-Soler J. Comparison of patients with and without papillary muscle rupture during acute myocardial infarction. Am J Cardiol 1997; 80:625-7.

10. Lamas G, Gary GF, Mitchell G, Flaker GC, Smith SC, Gersh $\mathrm{BJ}$ et al. Clinical significance of mitral regurgitation after acute myocardial infarction. Circulation, 1997; 96:827-833. 